Check for updates

Cite this: RSC Adv., 2018, 8, 4162

Received 3rd December 2017

Accepted 15th January 2018

DOI: $10.1039 / c 7 r a 12999 h$

rsc.li/rsc-advances

\section{Feasibility of hard acid-base affinity for the pronounced adsorption capacity of manganese(II) using amino-functionalized graphene oxide}

\author{
Anek Suddai, ${ }^{a}$ Prawit Nuengmatcha, ${ }^{\text {ab }}$ Phitchan Sricharoen, ${ }^{a}$ \\ Nunticha Limchoowong ${ }^{a}$ and Saksit Chanthai (D) *a
}

\begin{abstract}
The present study reveals the feasibility of using graphene oxide (GO) functionalized with 3-mercaptopropyl-trimethoxysilane (APTMS) for the removal of $\mathrm{Mn}(॥)$ from aqueous solution. The APTMS bound on GO's surface was successfully confirmed by FTIR and EDX. For an optimal adsorption study, the effects of $\mathrm{pH}(\mathrm{pH} 1-6)$, incubation time (5-80 min), temperature $\left(30-60{ }^{\circ} \mathrm{C}\right)$ and initial concentration of $\mathrm{Mn}\left(\right.$ ॥) (0.1-60 $\mathrm{mg} \mathrm{L}^{-1}$ ) were investigated in association with $\mathrm{Mn}$ measurement by AAS. The optimum conditions for $\mathrm{Mn}(\Perp)$ removal included a $20 \mathrm{mg} \mathrm{L}^{-1}$ initial concentration with $0.02 \mathrm{mg}$ adsorbent at $\mathrm{pH}$ 5.5, and complete adsorption equilibrium was reached within $50 \mathrm{~min}$. Their adsorption models are well described by both Langmuir and Freundlich isotherms. The maximum adsorption capacity of GO- $\mathrm{NH}_{2}$ for $\mathrm{Mn}(\mathrm{II})$ was $161.29 \mathrm{mg} \mathrm{g}^{-1}$, about 10 and 4 times higher than those of GP $\left(16.45 \mathrm{mg} \mathrm{g}^{-1}\right)$ and GO (41.67 $\mathrm{mg} \mathrm{g}^{-1}$ ) according to their relevant functional groups. For the $\mathrm{GO}-\mathrm{NH}_{2}$ adsorbent, the adsorption process of $\mathrm{Mn}(॥)$ follows a pseudo-second-order kinetics model, indicating that the overall rate of $\mathrm{Mn}(॥)$ uptake is controlled by external mass transfer at the initial stage of the adsorption. Later, the driving forces that control the adsorption rate are attributable to an intra-particle diffusion. A thermodynamic adsorption process reveals mainly an exothermic spontaneous reaction. Therefore, the present study provides an excellent adsorbent for $\mathrm{Mn}($ II) from aqueous solution. This adsorbent can also potentially be used for wastewater treatment.
\end{abstract}

\section{Introduction}

Manganese (Mn) is an abundant element in the Earth's crust and its presence in drinking water is a result of leaching processes depending on rock types. ${ }^{1}$ Although, it is an essential nutrient element in living systems that is found most often in the +2 valence among various oxidation states, elevated levels of Mn content can result in toxic neurological effects. ${ }^{2}$ There are many neurotoxic effects that cause a series of symptoms, such as adynamia, reduced coordination, masklike face, gait changes, sleep disturbances, muscular pain, hallucinations, and mental irritability, finally leading to a manganese-induced Parkinson like disease, called manganism. ${ }^{3}$ Therefore, it is necessary to remove $\mathrm{Mn}$ ion contaminants from wastewater before release into the environment.

Recently, numerous approaches have been studied for the development of effective technologies for pollutant removals. ${ }^{4-14}$

\footnotetext{
${ }^{a}$ Materials Chemistry Research Center, Department of Chemistry and Center of Excellence for Innovation in Chemistry, Faculty of Science, Khon Kaen University, Khon Kaen 40002, Thailand. E-mail: sakcha2@kku.ac.th

${ }^{b}$ Nanomaterials Chemistry Research Unit, Department of Chemistry, Faculty of Science and Technology, Nakhon Si Thammarat Rajabhat University, Nakhon Si Thammarat 80280, Thailand
}

Several common wastewater treatments for Mn(II) have been studied, such as solvent extraction, ${ }^{15}$ biological aerated filter, ${ }^{16}$ precipitation, ${ }^{17}$ coagulation/flocculation, ${ }^{18}$ flotation, ${ }^{19}$ ionexchange $^{20}$ and adsorption. ${ }^{21}$ Of these above techniques, adsorption technique provides an attractive alternative one to other removal techniques because it is more economical and readily available. ${ }^{22}$ This technique relies on interactions between adsorbent and adsorbate. Thus, a key factor in the adsorption process is selective adsorbent with its intrinsic functional groups. Several adsorbents that have been studied for $\mathrm{Mn}$ removal include fly ash, ${ }^{21}$ manganese oxide coated zeolite ${ }^{22}$ white rice husk ash, ${ }^{23}$ natural and modified zeolites, ${ }^{24}$ Pleurotus ostreatus nanoparticles, ${ }^{25}$ glycine modified chitosan resin $^{26}$ and phosphine-functionalized electrospun poly(vinyl alcohol)/silica nanofibers. ${ }^{27}$ However, some of these adsorbents are still either low efficiency or low adsorption capacity, thus new adsorbents have been developed to maximize their adsorption property with higher capacity and selectivity.

Graphene oxide (GO) is an alternative choice of the carbonbased adsorbents due to various functional groups (carbonyl, hydroxyl and epoxide) on their surface providing anchor sites for metal ion complexation. Thus, there are many applications of $\mathrm{GO}$ for toxic metal adsorption such as $\mathrm{Hg}(\mathrm{III}),{ }^{28} \mathrm{U}(\mathrm{VI}),{ }^{29} \mathrm{~Pb}(\mathrm{II}),{ }^{30}$ $\mathrm{Cd}(\mathrm{II}),{ }^{31} \mathrm{Cu}(\mathrm{II})$ and $\mathrm{Zn}(\mathrm{II}),{ }^{32} \mathrm{Au}(\mathrm{III}), \mathrm{Pd}(\mathrm{II})$ and $\mathrm{Pt}(\mathrm{Iv}){ }^{33}$ Moreover, 
GO can be modified with several ligands, making it a potential material as superb adsorbent for toxic metal ions removal such as 3-mercaptopropyl-trimethoxysilane, ${ }^{34} \mathrm{~N}$-(trimethoxysilylpropyl) ethylenediaminetriacetic acid, ${ }^{35}$ polyallylamine, ${ }^{36}$ $p$-phenylenediamine, ${ }^{37}$ polyhedral oligomeric silsesquioxane, ${ }^{38}$ hexamethylene diamine, ${ }^{39}$ polybenzimidazole, ${ }^{40}$ 2-amino-4,6didodecylamino-1,3,5-triazine ${ }^{\mathbf{4 1}}$ and other amino groups. ${ }^{\mathbf{4 2 - 4 4}}$ Particularly, the amino group $\left(-\mathrm{NH}_{2}\right)$ has high ability to adsorb both toxic metal ions and other pollutants. This unique characteristic reveals that the amino group has potential applications in the removal of pollutants from wastewater. Recently, many studies have tried to modify amino group on the surface of various materials for toxic pollutants removal and other applications such as mesoporous silica, ${ }^{45}$ silica, ${ }^{46} \mathrm{Fe}_{3} \mathrm{O}_{4},{ }^{47}$ mesoporous material SBA-16, ${ }^{48}$ multi-walled carbon nanotube, ${ }^{49}$ sawdust ${ }^{50}$ and $\mathrm{Fe}_{3} \mathrm{O}_{4} @ \mathrm{SiO}_{2},{ }^{51}$ indicating that the amino group is such high potential ligand for various applications.

In this study, the prepared GO was modified with 3-aminopropyl-trimethoxysilane (APTMS) to acquire the functionalized GO- $\mathrm{NH}_{2}$ and then applied to remove $\mathrm{Mn}$ (II) from aqueous solution. While there have been numerous papers reporting the fabrication of graphene-based adsorbents, there is no prior study on the synthesis of a GO-NH $\mathrm{H}_{2}$ adsorbent and its performance in the removal of $\mathrm{Mn}$ (II) from aqueous solution. Hence, in the present research, it is the first time for a proof-ofconcept study on the enhancement of adsorptive capacity of GO$\mathrm{NH}_{2}$ via a batch technique. An evaluation of the potential use of the GO- $\mathrm{NH}_{2}$ for $\mathrm{Mn}$ (II) removal in a batch adsorption study was compared with its bare graphite (GP) and graphene oxide (GO). The effects of solution $\mathrm{pH}$, incubation time and an initial concentration of $\mathrm{Mn}$ (II) were optimized in details. Both Langmuir and Freundlich isotherms were also investigated to fit their adsorption model for $\mathrm{Mn}$ (II) removal.

\section{Experimental}

\section{Chemicals and instrument}

Sodium nitrate, sulfuric acid, and hydrogen peroxide were purchased from Ajax FineChem Pty Ltd. Sodium acetate, acetic acid, potassium dihydrogen phosphate, di-potassium hydrogen phosphate anhydrous, ethanol, and methanol were purchased from QReC (New Zealand). Potassium permanganate and manganese chloride were purchased from Carlo Erba. Synthetic graphite power $(<20 \mu \mathrm{m})$ and (3-aminopropyl)trimethoxysilane were purchased from Sigma-Aldrich. All chemicals were used without further purification in all experiments. Manganese was determined using atomic absorption spectrophotometer (AAS), Perkin Elmer Instrument AA Analyst 100 (U.S.A.).

\section{Preparation and characterization of GO and GO-NH}

Graphene oxide was prepared from graphite powder by using the optimum conditions of our previous work $^{52}$ with the modified Hummers' method. ${ }^{53}$ In brief, $3.0 \mathrm{~g}$ of graphite powder and concentrated $\mathrm{H}_{2} \mathrm{SO}_{4}(300 \mathrm{~mL})$ were mixed in a beaker at $0{ }^{\circ} \mathrm{C}$ with vigorous magnetic stirring for $30 \mathrm{~min}$. Next, $3.0 \mathrm{~g}$ of $\mathrm{NaNO}_{3}$ was added portion-wise to the mixture and kept further stirring for $30 \mathrm{~min}$. Then, a solid powder of $\mathrm{KMnO}_{4}$ was slowly added to the beaker and the mixture was kept below $15^{\circ} \mathrm{C}$. The mixture was stirred at $35{ }^{\circ} \mathrm{C}$ until its colour changed to brown, and then the mixture was diluted with $200 \mathrm{~mL}$ of deionized water was then slowly added to the mixture and stirred again for $30 \mathrm{~min}$. After heating up to $80{ }^{\circ} \mathrm{C}$ for $6 \mathrm{~h}, 40 \mathrm{~mL}$ of $30 \% \mathrm{H}_{2} \mathrm{O}_{2}$ was slowly added. The solution mixture was centrifuged and washed several times with deionized water until the $\mathrm{pH}$ of the filtrate reached neutral. Then, the lyophilized precipitates were obtained.

To functionalize GO with APTMS, $200 \mathrm{mg}$ of GO was added to round flask with $25 \mathrm{~mL}$ ethanol and dispersed through ultrasonication for $30 \mathrm{~min}$. Then $4.5 \% \mathrm{w} / \mathrm{v}$ of APTMS was added and ultrasonicated next for $30 \mathrm{~min}$. After that the mixture stirred at $65{ }^{\circ} \mathrm{C}$ for $12 \mathrm{~h}$. The GO- $\mathrm{NH}_{2}$ product was centrifuged and washed with ethanol and oven-dried at $50{ }^{\circ} \mathrm{C}$ for $12 \mathrm{~h}$. The obtained GO-NH $\mathrm{H}_{2}$ was characterized by FTIR and EDX techniques.

\section{Adsorption experiments}

The effects of experimental parameters such as $\mathrm{pH}$ of solution (1-6), incubation time $(0-80 \mathrm{~min})$ and temperature $\left(30-60{ }^{\circ} \mathrm{C}\right)$ on the adsorptive removal of $\mathrm{Mn}$ (II) ions were studied in a batch mode of operation for a specific period of $\mathrm{Mn}$ (II) concentration of $10 \mathrm{mg} \mathrm{L}{ }^{-1}$. All adsorption experiments were conducted in $125 \mathrm{~mL}$ conical flask, adsorbent $(0.02 \mathrm{~g})$ was accurately weighed into a conical flask. Then, $25 \mathrm{~mL}$ of $\mathrm{Mn}$ (II) solution was added and the $\mathrm{pH}$ of the solution was adjusted and shaken by an orbital shaker at approximately $200 \mathrm{rpm}$ at ambient temperature. After a period of shaking, the adsorbent was separated from the solution mixture by centrifugation for $5 \mathrm{~min}$ and $\mathrm{Mn}$ (II) in the supernatant solution was determined by AAS. All experiments were conducted in triplicate under the same conditions. The adsorption capacity $\left(q_{\mathrm{e}}, \mathrm{mg}^{-1}\right)$ of $\mathrm{Mn}(\mathrm{II})$ at an equilibrium state was determined as follows:

$$
q_{\mathrm{e}}=V\left(C_{0}-C_{\mathrm{e}}\right) / m
$$

where, $C_{0}$ is the initial concentration $\left(\mathrm{mg} \mathrm{L}^{-1}\right)$ of $\mathrm{Mn}$ (II) in the solution, $C_{\mathrm{e}}$ is the $\mathrm{Mn}(\mathrm{II})$ concentration $\left(\mathrm{mg} \mathrm{L}^{-1}\right)$ at the equilibrium state, $V$ is the volume (L) of the solution, and $m$ is the mass (g) of the adsorbent. Langmuir and Freundlich adsorption models were used to describe the equilibrium nature of $\mathrm{Mn}$ (II) adsorption onto the GO- $\mathrm{NH}_{2}$ compared with graphene oxide and graphite used as background reference.

\section{Results and discussion}

\section{Characterization of adsorbents}

In this work, FTIR and EDX spectral data demonstrated the element contents and functional groups of the raw material and the functionalized GO-NH$H_{2}$. FTIR spectra of these adsorbents are shown in Fig. 1. It is evident that changes in the adsorption peaks of APTMS, GO-APTMS, GO and GP are differently observed. The peak at $3388 \mathrm{~cm}^{-1}$ is the stretching of $-\mathrm{OH}$ groups. Peaks for $\mathrm{C}-\mathrm{H}$ stretching vibration of $\mathrm{CH}_{3}$ and $\mathrm{CH}_{2}$ groups appear at $2939 \mathrm{~cm}^{-1}$ and $2839 \mathrm{~cm}^{-1}$, respectively. The band at $1124 \mathrm{~cm}^{-1}$ is the stretching vibration of $\mathrm{Si}-\mathrm{O}-\mathrm{C}$, 


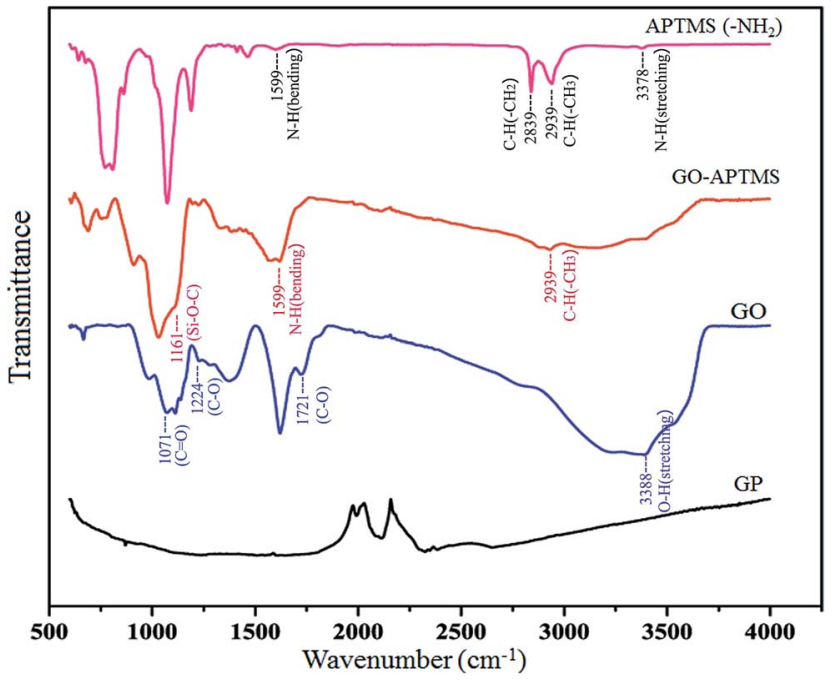

Fig. 1 FTIR spectra of GP, GO, GO-APTMS and APTMS. confirming the formation of GO-APTMS. Moreover, it is noted in their spectra of APTMS and GO-SPTMS the stretching vibration of $-\mathrm{NH}_{2}$ group occurs at $1599 \mathrm{~cm}^{-1}$ which proves the existence of the functionalized $\mathrm{NH}_{2}$ groups on the GO surface.

Furthermore, from EDX patterns in Fig. 2, it is shown that changes in the spectral data of GP, GO and GO-APTMS are also obviously different. The peaks of $\mathrm{Si}$ and $\mathrm{N}$ occur only in GOAPTMS, indicating that graphene oxide modified with amino is successfully obtained. This observation suggests that graphene oxide contains the $\mathrm{NH}_{2}$ group attached, which can be applied to selectively remove Mn(II) from aqueous solution.

\section{Adsorption experiment}

Effect of pH. It is well known that the adsorption of toxic metal ions depends on the $\mathrm{pH}$ of solution. The influence of $\mathrm{pH}$ on the adsorption efficiency was evaluated in terms of adsorption capacity. Fig. 3 shows the adsorption capacity of Mn(II) at different $\mathrm{pH}$ values in the range of 1-6. It was found that the adsorption of $\mathrm{Mn}$ (II) increased with the $\mathrm{pH}$ of the solution. For
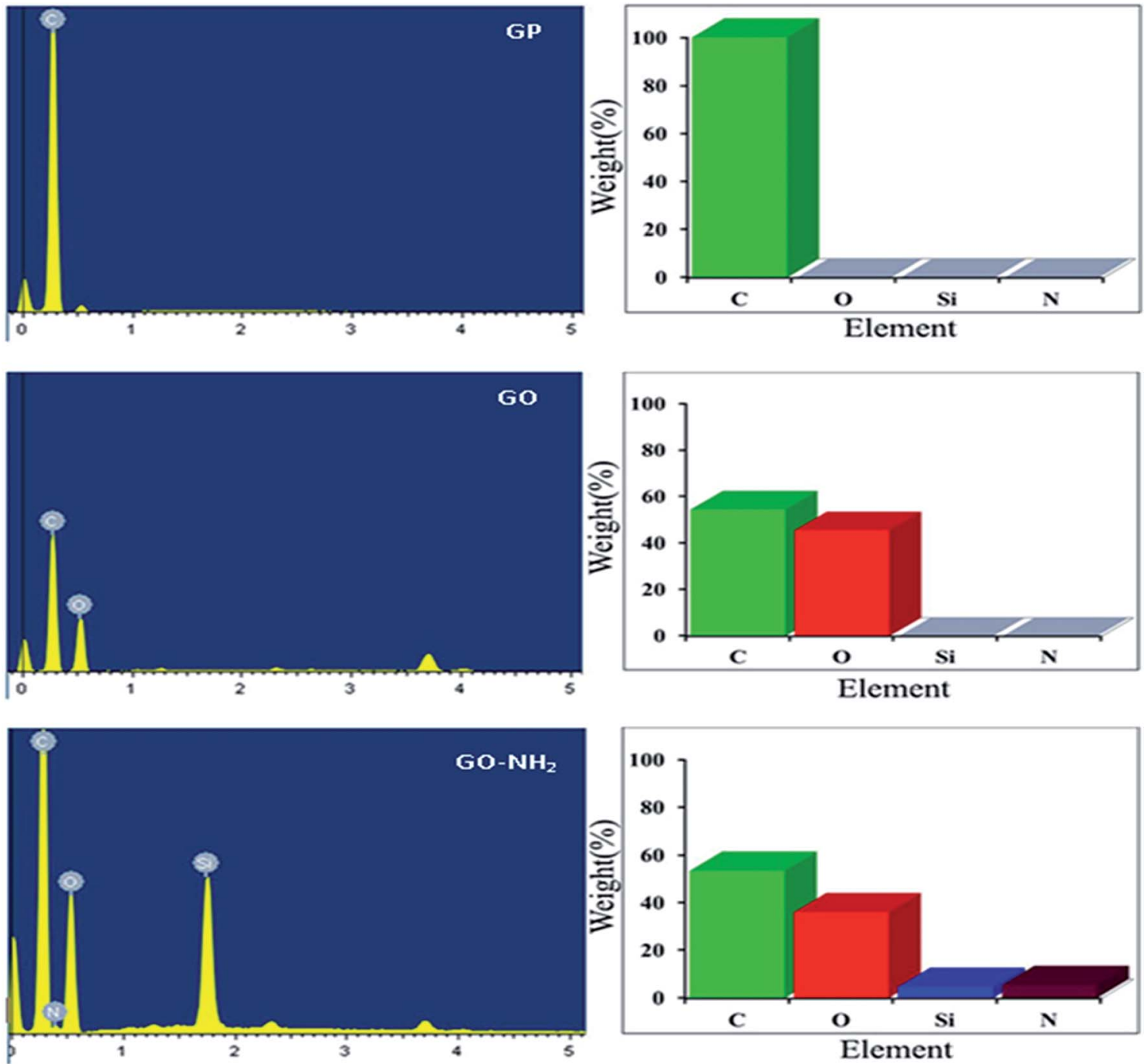

Fig. 2 EDX patterns of $\mathrm{GP}, \mathrm{GO}$ and $\mathrm{GO}-\mathrm{NH}_{2}$. 


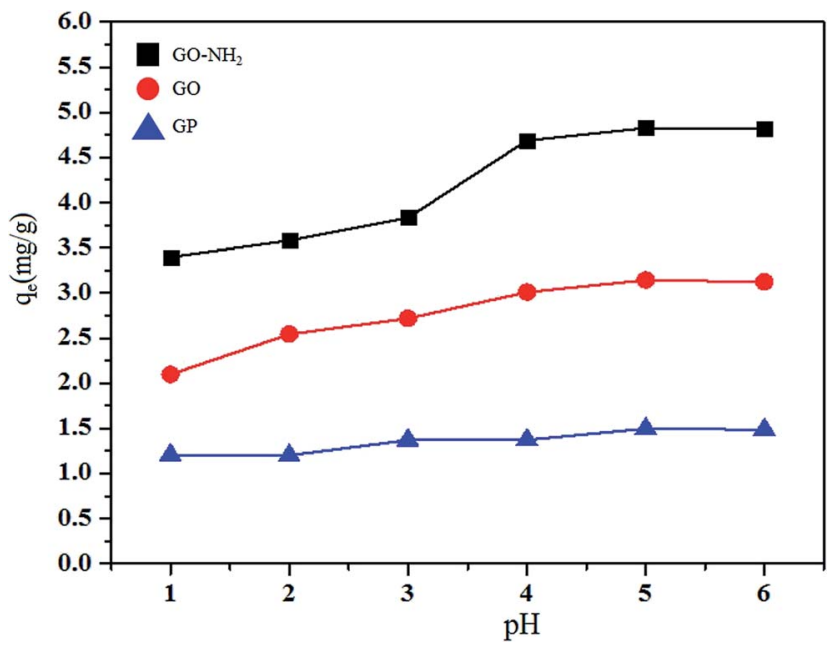

Fig. 3 Effect of $\mathrm{pH}$ on adsorption of $\mathrm{Mn}(\mathrm{I})$ using $\mathrm{GP}, \mathrm{GO}$ and $\mathrm{GO}-\mathrm{NH}_{2}$ as adsorbents.

all adsorbents studied, at $\mathrm{pH}>5$, the maximum uptake is attained and maintained constant. However, the adsorption capacity of $\mathrm{GO}-\mathrm{NH}_{2}$ drastically changes in the $\mathrm{pH}$ range 3-4 which may be due to the competition between $\mathrm{H}^{+}$and $\mathrm{Mn}^{2+}$ ions for their adsorption sites causing in decrease of the adsorption. In addition, at acidic solution, the adsorbent surface becomes positively charged and not favored uptake of $\mathrm{Mn}$ (II). On the other hand, at higher $\mathrm{pH}$, surface of the adsorbent had got negatively charged and favored uptake of $\mathrm{Mn}$ (II). The maximum adsorption capacity occurred at pH 5.5, 5.0 and 5.5 for GP, GO and GO- $\mathrm{NH}_{2}$, respectively. Therefore, it was chosen as the optimal value for further adsorption studies.

Effect of incubation time. The effect of incubation time on the amount of $\mathrm{Mn}$ (II) adsorbed was investigated at the optimal $\mathrm{pH}$ as shown in Fig. 4. It was evident that the Mn(II) uptake by these adsorbents increased with increasing incubation time, with their equilibrium state being established within 60, 30 and

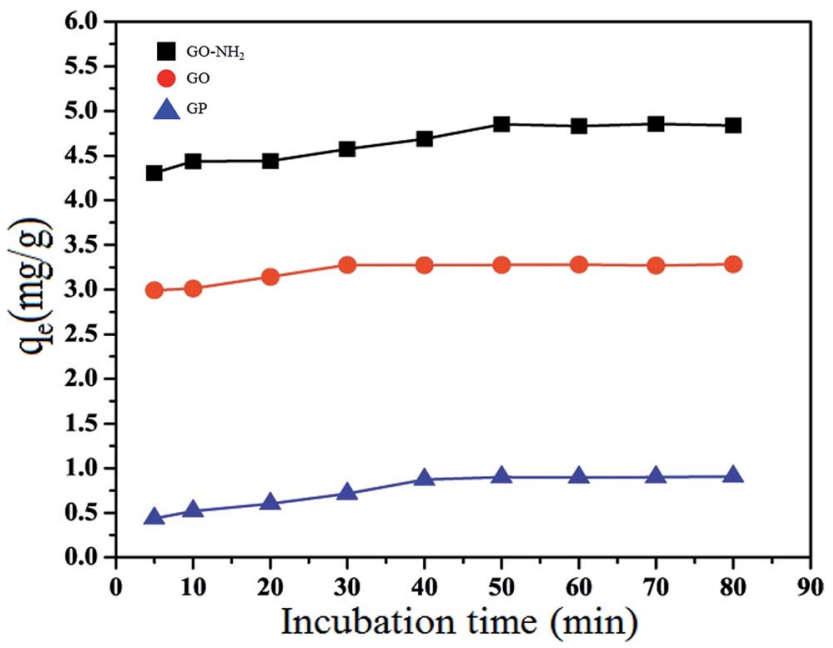

Fig. 4 Effect of incubation time on adsorption of $\mathrm{Mn}(॥)$ using GP, GO and $\mathrm{GO}-\mathrm{NH}_{2}$ as adsorbents.
50 min for GP, GO and GO- $\mathrm{NH}_{2}$, respectively. At the initial stage (about $30 \mathrm{~min}$ ), the $\mathrm{Mn}$ (II) adsorption rate may be explained by an increased availability in the number of active sites on the surface of the adsorbent. The adsorption amount of Mn(II) on the adsorbent increased and normally controlled by diffusion process from the bulk to the surface of the adsorbent. At the final stage, the adsorption amount of $\mathrm{Mn}$ (II) was likely an attachment controlled process due to less available sorption sites. ${ }^{54}$ Therefore, further studies were carried out within $60 \mathrm{~min}$ for all adsorbents to ensure the attainment of the equilibrium conditions.

Effect of temperature. Temperature has a pronounced effect on the removal of pollutant species from aqueous solutions with most adsorption processes being exothermic in nature. ${ }^{55,56}$ The study of the present process also revealed its exothermic nature as shown in Fig. 5. It was found that the adsorption capacities of GP, GO and GO- $\mathrm{NH}_{2}$ decreased with an increasing temperature. The reason behinds this appearance is that common thermal effect on their binding energy caused by collision principle, in particular for weak physisorption of the adsorption capacity. The results indicate that at lower temperatures that favor the removal of $\mathrm{Mn}$ (II) by the adsorption process are exothermic nature. While at high temperatures, the decreasing of removal efficiency may be due to the decrease in the thickness of the boundary layer that increases tendency of the molecules to escape from the adsorbent surface to the bulk solution. ${ }^{57}$ The maximum adsorption capacity occurred at $30{ }^{\circ} \mathrm{C}$ for all adsorbents therefore, it was chosen as the optimal value for further adsorption studies.

Thermodynamic study. In order to study the effect of temperature on the adsorption of $\mathrm{Mn}$ (II) onto adsorbents, the thermodynamic parameters including Gibbs free energy change $\left(\Delta G^{0}\right)$, entropy change $\left(\Delta S^{0}\right)$ and enthalpy change $\left(\Delta H^{0}\right)$ were calculated using the following equations:

$$
\Delta G^{0}=-R T \ln K_{\mathrm{d}}
$$

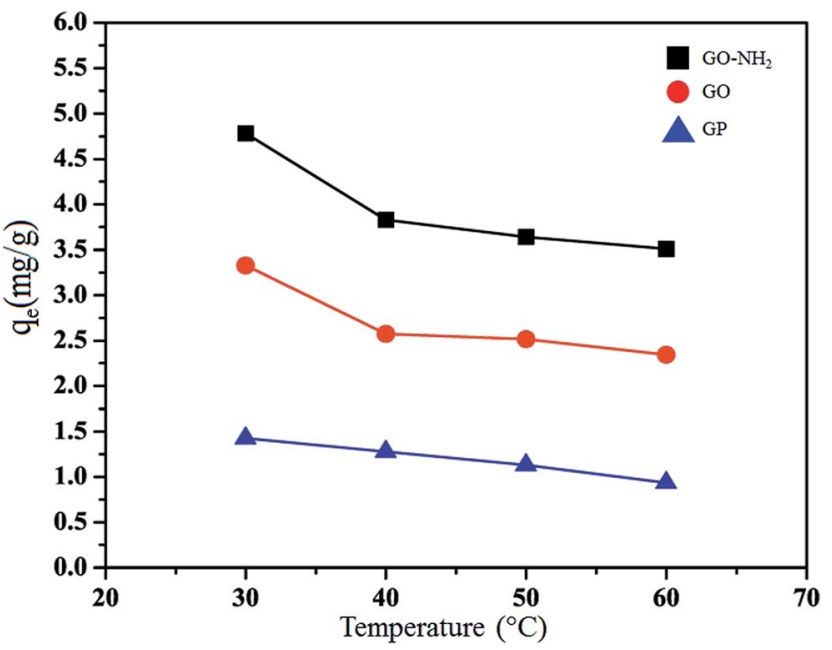

Fig. 5 Effect of temperature on adsorption of Mn(॥) using GP, GO and $\mathrm{GO}-\mathrm{NH}_{2}$ as adsorbents. 


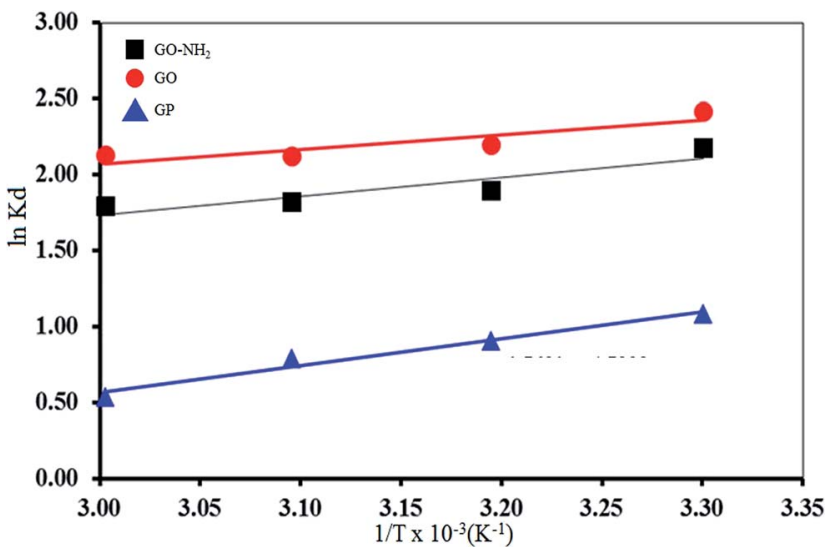

Fig. 6 Plot of $\ln K_{\mathrm{d}}$ versus $1 / T$ for the $\mathrm{Mn}($ (I) adsorption onto GP, GO and $\mathrm{GO}-\mathrm{NH}_{2}$.

$$
\begin{gathered}
K_{\mathrm{d}}=q_{\mathrm{e}} / C_{\mathrm{e}} \\
\ln K_{\mathrm{d}}=-\Delta H^{0} / R T+\Delta S^{0} / R
\end{gathered}
$$

where, $R$ is the gas constant $\left(8.314 \mathrm{~J} \mathrm{~mol}^{-1} \mathrm{~K}^{-1}\right), T$ is absolute temperature in $\mathrm{K}$ and $K_{\mathrm{d}}$ is the equilibrium constant. $q_{\mathrm{e}}$ is the amount of the $\mathrm{Mn}$ (II) (mg) adsorbed per gram of adsorbent at equilibrium, $C_{\mathrm{e}}$ is the equilibrium concentration $\left(\mathrm{mg} \mathrm{L}^{-1}\right)$ of the $\mathrm{Mn}(\mathrm{II})$ in solution.

The values of $\Delta S^{0}$ and $\Delta H^{0}$ can be calculated from the slope and the intercept of the van't Hoff plot of $\ln K_{\mathrm{d}}$ versus $1 / T$ (Fig. 6), respectively.

Table 1 shows the obtained thermodynamic parameters of GP, GO and $\mathrm{GO}-\mathrm{NH}_{2}$. It was found that negative $\Delta G^{0}$ of all adsorbents indicates the spontaneity of the ongoing adsorption process. ${ }^{58}$ Negative value of $\Delta S^{0}$ indicates a tendency to lower disorder at the solid-solution interface during the adsorption. ${ }^{59}$ In addition, the negative $\Delta H^{0}$ indicates that the Mn(II) adsorption using GP, GO and GO-NH${ }_{2}$ are the exothermic nature, the low values of $\Delta H^{0}$ give clearly evidence that the interactions between $\mathrm{Mn}$ (II) and its adsorbent were rather weak. ${ }^{60,61}$

Kinetic study. Several kinetic models have been applied to examine the controlled mechanism of metal ions adsorption from aqueous solution. In this study, pseudo-first-order, pseudo-second-order, and intra-particle diffusion were applied.

The pseudo first-order equation describes adsorption in solid-liquid systems based on the sorption capacity of solids. It has been proposed that only one ion of the metal is sorbed onto one sorption site on the adsorbent surface. The linear form of

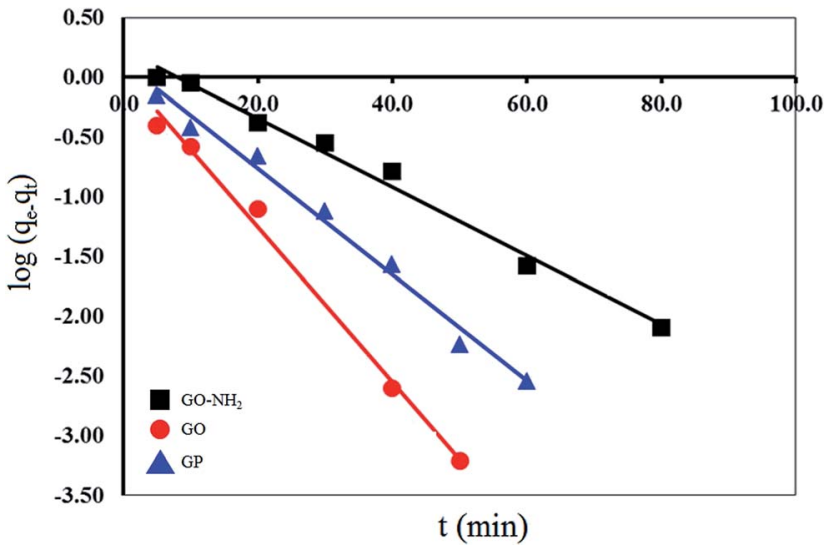

Fig. 7 The first-order kinetic data of $\mathrm{Mn}(॥)$ adsorption using GP, GO and $\mathrm{GO}-\mathrm{NH}_{2}$ at $303 \mathrm{~K}$.

the pseudo first-order models can be written by the following eqn (5):

$$
\log \left(q_{\mathrm{e}}-q_{\mathrm{t}}\right)=\log q_{\mathrm{e}}-\left(k_{1} / 2.303\right) t
$$

where, $k_{1}$ is the rate constant $\left(\mathrm{L} \mathrm{min}^{-1}\right)$ of the pseudo-first order adsorption, $q_{\mathrm{e}}$ and $q_{t}$ are the amounts of Mn(II) adsorbed onto adsorbent at an equilibrium state $\left(\mathrm{mg} \mathrm{g}^{-1}\right)$ and at time $t$, respectively. The values of $k_{1}$ and $q_{\mathrm{e}}$ are calculated from slope and intercept of the plot of $\log \left(q_{\mathrm{e}}-q_{t}\right)$ versus $t$ (Fig. 7), respectively.

The pseudo second-order rate expression has been applied for analyzing chemi-sorption kinetics from liquid solutions. From the assumption of this model, only one ion of the metal is sorbed onto two sorption sites on the adsorbent surface. The linear form of the pseudo second-order models can be written by the following eqn (6):

$$
t / q_{t}=\left(1 / k_{2} q_{2}^{2}\right)+\left(t / q_{2}\right)
$$

where, $q_{2}$ is the maximum adsorption capacity $\left(\mathrm{mg} \mathrm{g}^{-1}\right)$ for pseudo-second-order adsorption, $q_{t}$ is the amount of $\mathrm{Mn}$ (II) adsorbed at equilibrium state $\left(\mathrm{mg} \mathrm{g}^{-1}\right)$ at time $t(\mathrm{~min})$ and $k_{2}$ is the rate constant of the pseudo-second-order adsorption $(\mathrm{g}$ $\mathrm{mg}^{-1} \mathrm{~min}^{-1}$ ). The values of $k_{2}$ and $q_{2}$ were calculated from the slope and intercept of the plot (Fig. 8) of $t / q_{t}$ versus $t$, respectively.

The kinetic parameters for the $\mathrm{Mn}$ (II) adsorption of GO at 303 $\mathrm{K}$ were calculated from eqn (5) and (6) as shown in Table 2. It is found that the pseudo-first order kinetic model is applicable for

Table 1 Thermodynamic parameters of $\mathrm{Mn}(\mathrm{I})$ adsorption using GP, GO and GO- $\mathrm{NH}_{2}$

$$
\Delta G^{0}\left(\mathrm{~kJ} \mathrm{~mol}^{-1}\right)
$$

\begin{tabular}{lllllrrr} 
Adsorbent & $\Delta H^{0}\left(\mathrm{~kJ} \mathrm{~mol}^{-1}\right)$ & $\Delta S^{0}\left(\mathrm{~kJ} \mathrm{~mol}^{-1} \mathrm{~K}^{-1}\right)$ & $303 \mathrm{~K}$ & $313 \mathrm{~K}$ & $323 \mathrm{~K}$ & $333 \mathrm{~K}$ \\
\hline GP & -14.71 & -39.41 & -20.14 & -20.33 & -20.67 & -20.62 \\
GO & -8.08 & -7.03 & -23.69 & -23.30 & -24.17 & -25.01 \\
GO-NH & -10.45 & -16.97 & -22.87 & -22.91 & -23.43 & -24.07
\end{tabular}




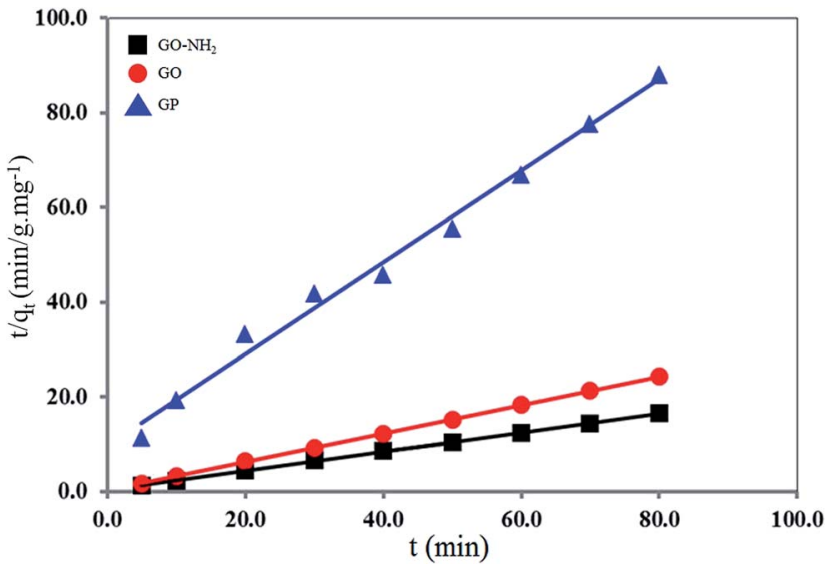

Fig. 8 The pseudo-second-order kinetic data of $\mathrm{Mn}(॥)$ adsorption using $\mathrm{GP}, \mathrm{GO}$ and $\mathrm{GO}-\mathrm{NH}_{2}$ at $303 \mathrm{~K}$.

only the adsorption of $\mathrm{Mn}$ (II) by GP, because its calculated maximum adsorption capacity $\left(q_{1}=1.32 \mathrm{mg} \mathrm{g}^{-1}\right)$ and the experimental adsorption capacity $\left(q_{\mathrm{e}, \exp }=0.90 \mathrm{mg} \mathrm{g}^{-1}\right)$ are close. On the other hand, the adsorption of Mn(II) by GO and GO- $\mathrm{NH}_{2}$ fitted well with the pseudo-second-order kinetic model. The $q_{2}$ value of GO and GO-NH $\mathrm{N}_{2}$ are 3.33 and $4.94 \mathrm{mg} \mathrm{g}^{-1}$ and the linear correlation coefficient $\left(R^{2}\right)$ of 0.9999 and 0.9995 are high. Moreover, both of the calculated ( 3.33 for GO and $4.94 \mathrm{mg}$ $\mathrm{g}^{-1}$ for GO-NH$\left.{ }_{2}\right)$ and the experimental $\left(q_{\mathrm{e}, \text { exp }} ; 3.28 \mathrm{mg} \mathrm{g}^{-1}\right.$ for $\mathrm{GO}$ and $4.85 \mathrm{mg} \mathrm{g}^{-1}$ for $\mathrm{GO}-\mathrm{NH}_{2}$ ) values are close to each other.

In order to gain insight into both the mechanism and rate controlling step affecting the kinetics of adsorption, the Weber's intra-particle diffusion model was applied to the kinetic experiment. The kinetic results were analyzed by the intra-particle diffusion model to elucidate the diffusion mechanism. The intra-particle diffusion model is expressed as following eqn (7):

$$
q_{t}=k_{\mathrm{p}} t^{1 / 2}+C
$$

where, $q_{t}$ is the amount of $\mathrm{Mn}(\mathrm{II})$ adsorbed at an equilibrium $\left(\mathrm{mg} \mathrm{g}^{-1}\right)$ at time $t, C$ is the intercept and $k_{\mathrm{p}}$ is the intra-particle diffusion rate constant in $\mathrm{mg}\left(\mathrm{g}^{-1} \mathrm{~min}^{1 / 2}\right)$. The values of $k_{\mathrm{p}}$ and $C$ of the intra-particle diffusion were calculated from slope and intercept of the plot (Fig. 9) of $q_{t}$ versus $t^{1 / 2}$. If the linear plot goes through the origin, it reflects that the rate limiting step is only due to the intra-particle diffusion. On the other hand, the larger the intercept is obtained, the greater the contribution of the surface sorption in the rate-limiting step. ${ }^{62}$
Fig. 9 shows the intra-particle diffusion for Mn(II) adsorption using GP, GO and GO-NH $\mathrm{N}_{2}$ used as adsorbents. The trend of the adsorption process is defined as three phases occurring during the adsorption process. The first portion is a transport of the $\mathrm{Mn}$ (II) ions from the bulk solution onto the external surface of adsorbent by diffusion through the boundary layer. The second one is the diffusion of the Mn(II) ions from the external surface into the pores of the adsorbents. The last one is the final equilibrium stage, where $\mathrm{Mn}$ (II) ions were adsorbed on the active sites on the internal surface of the pore, and the intraparticle diffusion plot starts slowing down due to the solute concentration getting lower in the solution..$^{63}$ The surface adsorption was predominantly occurred within 60,30 and 50 min contact time for GP, GO and $\mathrm{GO}-\mathrm{NH}_{2}$, respectively. Thereafter, the diffusion route became the rate-limiting step. The intra-particle diffusion rate constant $k_{\mathrm{p}}\left(\mathrm{mg} \mathrm{g}^{-1} \mathrm{~min}^{-1 / 2}\right)$ was evaluated from the slope of the second linear part of the plotting of $q_{t}$ versus $t^{1 / 2}$ (Table 3). As the plot did not pass through the origin, the intra-particle diffusion was not the only rate-limiting step. Thus, there were three processes on controlling the adsorption rate but only one was the rate limiting in any particular time range. In addition, the intercept of the plot indicates the boundary layer effect. The value of $\mathrm{C}$ was highest for GO- $\mathrm{NH}_{2}$, resulting in more surface adsorption of the Mn(II). Therefore, both surface adsorption and intra-particle diffusion mechanisms were simultaneously cooperated in the adsorption behaviors.

Adsorption isotherm. The interactions between liquid phase and adsorbent are described by the adsorption isotherms. The theoretical Langmuir and empirical Freundlich isotherms were used to model the adsorption equilibrium. The Langmuir model assumes that a monolayer of adsorbate is covered on a homogenous adsorbent surface. In addition, this model assumes uniform energies of sorption onto the surface and no transmigration of adsorbate within the plane of the surface. The adsorption takes place only at specific sites of the adsorbent, which is valid for monolayer sorption onto a surface, given by eqn (8):

$$
C_{\mathrm{e}} / q_{\mathrm{e}}=C_{\mathrm{e}} / q_{\mathrm{m}}+1 / q_{\mathrm{m}} K_{\mathrm{L}}
$$

where, $q_{\mathrm{m}}$ is the maximum amount of $\mathrm{Mn}$ (II) absorbed per unit weight of adsorbent $\left(\mathrm{mg} \mathrm{g}^{-1}\right)$ to form a complete monolayer covered on the surface at equilibrium $\mathrm{Mn}$ (II) concentration, $C_{\mathrm{e}}$ $\left(\mathrm{mg} \mathrm{L}^{-1}\right), q_{\mathrm{e}}$ is the amount of $\mathrm{Mn}(\mathrm{II})$ adsorbed per unit weight of adsorbent at equilibrium, and $K_{\mathrm{L}}$ is the Langmuir constant $\left(\mathrm{L} \mathrm{mg}^{-1}\right)$ related to the surface affinity for $\mathrm{Mn}(\mathrm{II})$. The value of $q_{\mathrm{m}}$

Table 2 The kinetic parameters of $\mathrm{Mn}\left(\right.$ (I) adsorption using GP, GO and GO- $\mathrm{NH}_{2}$

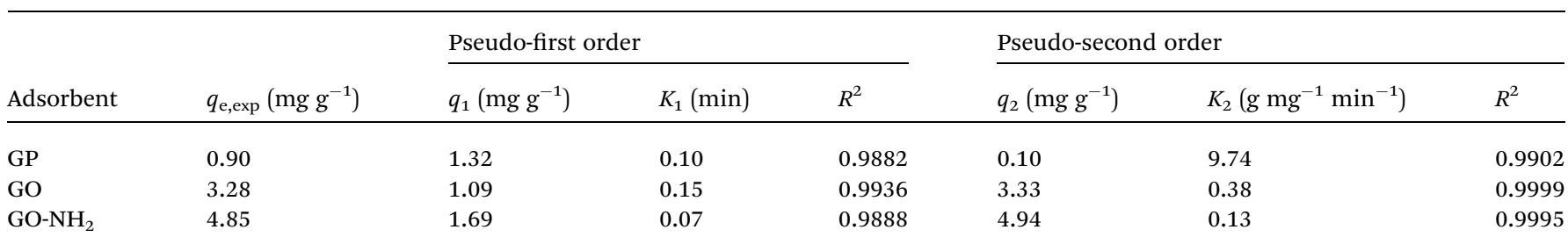



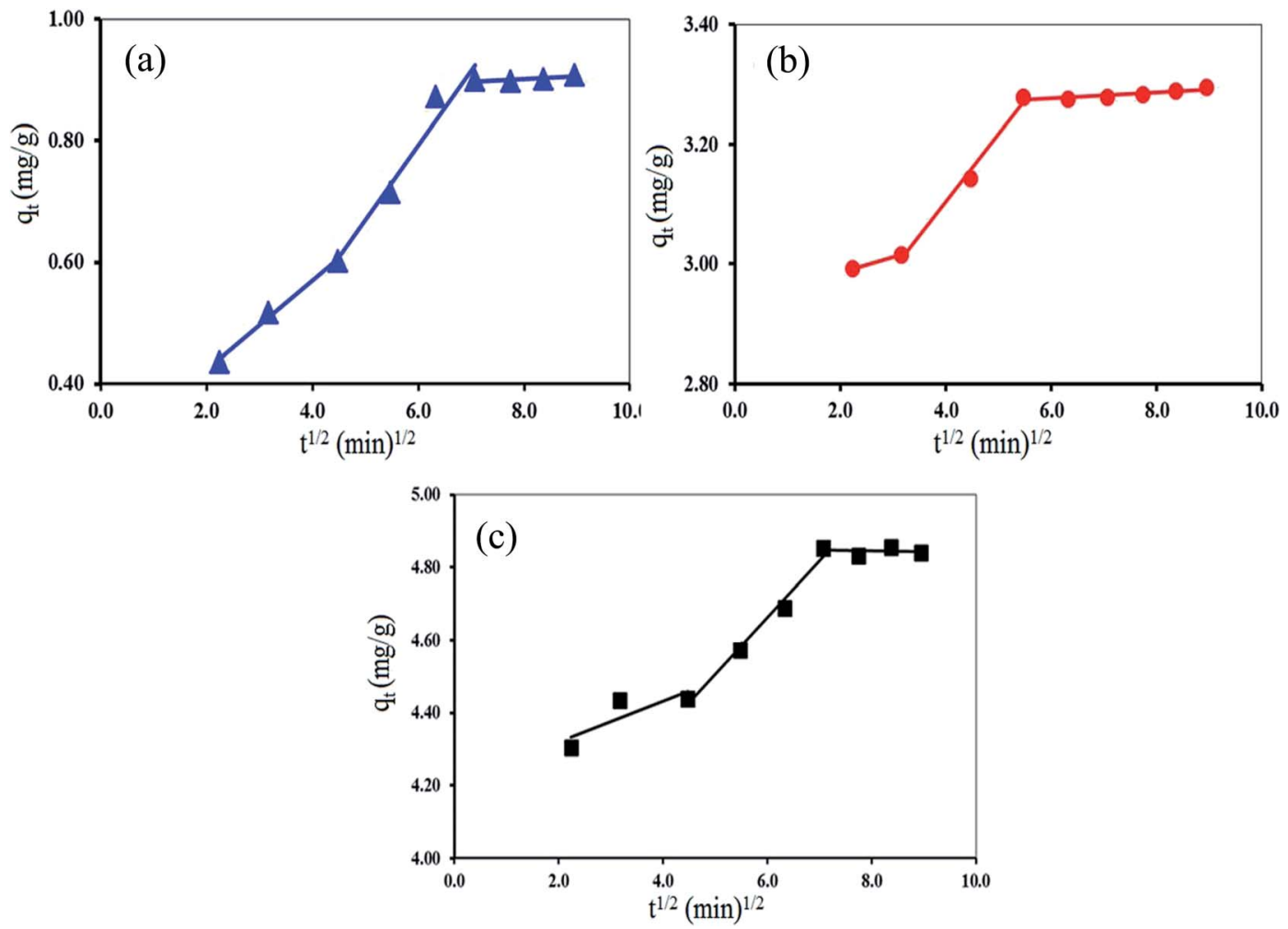

Fig. 9 Intra-particle diffusion kinetic model of $\mathrm{Mn}($ (I) adsorption using (a) GP, (b) GO and (c) GO-NH .

Table 3 The intraparticle diffusion parameters of $\mathrm{Mn}(\Perp)$ adsorption using $\mathrm{GP}, \mathrm{GO}$ and $\mathrm{GO}-\mathrm{NH}_{2}$

\begin{tabular}{llll}
\hline & Parameter & \\
\cline { 2 - 4 } Adsorbent & $K_{\mathrm{p}}\left(\mathrm{mg} \mathrm{g}^{-1} \mathrm{~min}^{-1 / 2}\right)$ & $C\left(\mathrm{mg} \mathrm{g}^{-1}\right)$ & $R^{2}$ \\
\hline GP & 0.12 & 0.06 & 0.9589 \\
GO & 0.11 & 2.65 & 0.9915 \\
GO-NH & 0.16 & 3.73 & 0.9852
\end{tabular}

represents a practical limiting adsorption capacity when the surface is fully covered with $\mathrm{Mn}$ (II) ions. The values of $q_{\mathrm{m}}$ and $K_{\mathrm{L}}$ are calculated from the slopes and the intercepts of the straight line of the plots of $C_{\mathrm{e}} / q_{\mathrm{e}}$ versus $C_{\mathrm{e}}$, respectively.

The Freundlich adsorption isotherm is used to describe the adsorption characteristics for the heterogeneous surface. These data often fit the empirical eqn (9) proposed by Freundlich:

$$
\log q_{\mathrm{e}}=\log K_{\mathrm{F}}+(1 / n) \log C_{\mathrm{e}}
$$

where, $C_{\mathrm{e}}$ is the equilibrium concentration of adsorbate. $q_{\mathrm{e}}$ is the amount of $\mathrm{Mn}$ (II) adsorbed per gram of the adsorbent at equilibrium. $K_{\mathrm{F}}$ and $n$ are the Freundlich constants and adsorption intensity, respectively. Both values of $K_{\mathrm{F}}$ and $1 / n$ (between 0 and 1) can be obtained from the linear plots of $\log q_{\mathrm{e}}$ versus $\log C_{\mathrm{e}}$.

The constant $K_{\mathrm{F}}$ is an approximate indicator of adsorption capacity, while $1 / n$ is a function of the strength of adsorption in the adsorption process. If $n=1$, then the partition between the two phases is independent of the concentration. If the value of $1 / n$ is below one, it indicates a normal adsorption. On the other hand, $1 / n$ being above one indicates cooperative adsorption. However, $K_{\mathrm{F}}$ and $n$ are the characteristic factors of the sorbent-sorbate system, which must be determined by data fitting. Specifically, the linear least-square method and the linearly transformed equations have been widely applied to correlate sorption data where $1 / n$ is a heterogeneity parameter; the smaller the $1 / n$, the greater the expected heterogeneity.

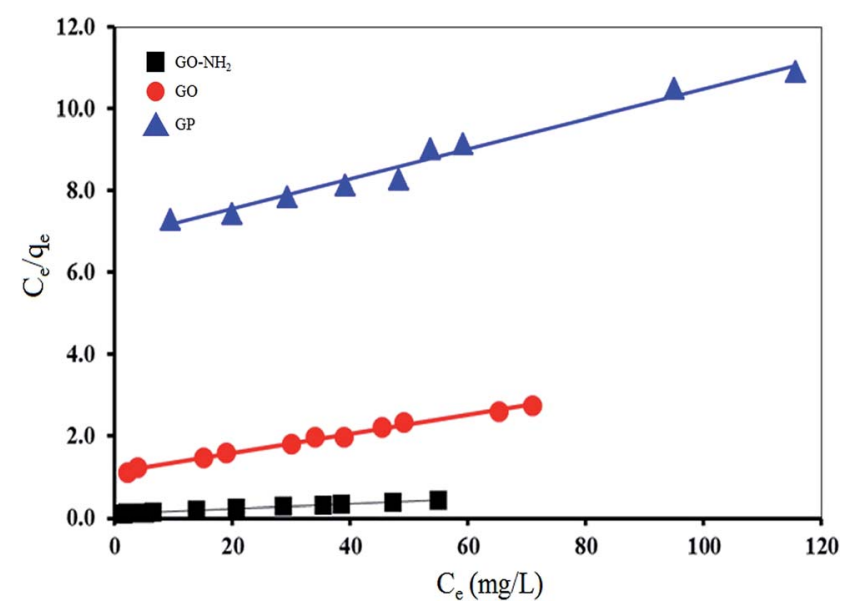

Fig. 10 Langmuir plot of $\mathrm{Mn}(\Perp)$ using $\mathrm{GP}, \mathrm{GO}$ and $\mathrm{GO}-\mathrm{NH}_{2}$ as adsorbents. 


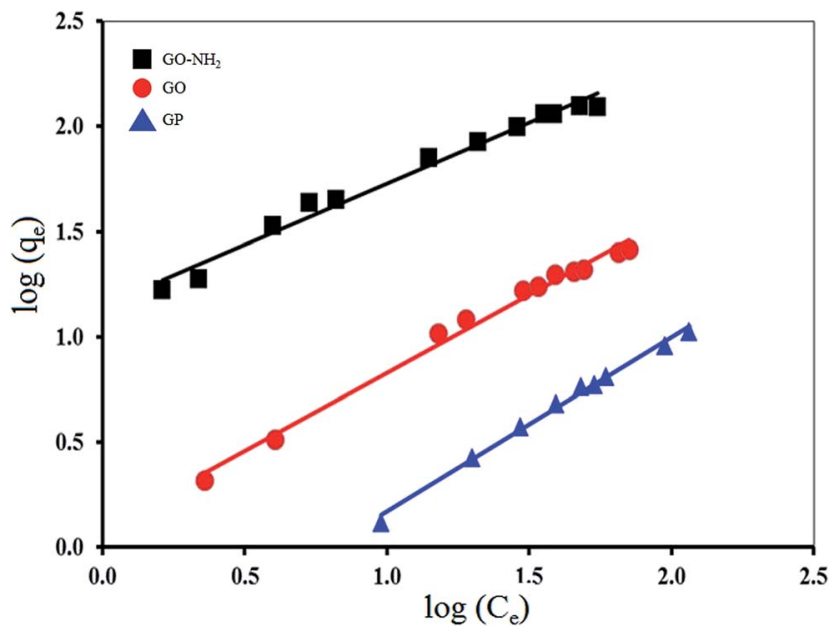

Fig. 11 Freundlich plot of $\mathrm{Mn}(\Perp)$ using GP, GO and $\mathrm{GO}-\mathrm{NH}_{2}$ as adsorbents.

This expression reduces to a linear adsorption isotherm when $1 / n=1 .{ }^{57}$

Fig. 10 and 11 show the fitting plots of Langmuir adsorption and Freundlich adsorption of Mn(II) onto GP, GO and GO-NH ${ }_{2}$. The constant values obtained from both Langmuir and Freundlich adsorption isotherms and their correlation coefficients $\left(R^{2}\right)$ were calculated and are summarized in Table 4 .

From the results, it can be concluded that for GP adsorbent, Freundlich isotherm $\left(R^{2}>0.94\right)$ fitted the experimental results better than Langmuir isotherm $\left(R^{2}>0.87\right)$. It corresponds to the greater heterogeneity of the adsorbent surface. On the other hand, for GO and GO- $\mathrm{NH}_{2}$ adsorbents, Langmuir isotherm $\left(R^{2}>\right.$ 0.98) fitted the experimental results better than Freundlich

Table 4 Langmuir and Freundlich isotherms for $\mathrm{Mn}(॥)$ adsorption models

\begin{tabular}{lllllllll}
\hline & \multicolumn{2}{l}{ Langmuir Isotherm } & & \multicolumn{3}{l}{ Freundlich Isotherm } \\
\cline { 2 - 3 } Adsorbent & $q_{\max }\left(\mathrm{mg} \mathrm{g}^{-1}\right)$ & $K_{\mathrm{L}}$ & $R^{2}$ & & $K_{\mathrm{F}}$ & $1 / n$ & $R^{2}$ \\
\hline GP & 16.45 & 0.0102 & 0.8730 & & 0.122 & 1.0412 & 0.9435 \\
GO & 41.67 & 0.0213 & 0.9765 & 2.992 & 0.8773 & 0.8773 \\
GO-NH & 161.29 & 0.0643 & 0.9854 & & 2.632 & 1.2176 & 0.9006
\end{tabular}

Table 5 The adsorption capacity of $\mathrm{Mn}(॥)$ using various carbon-based adsorbents

\begin{tabular}{lcl}
\hline Adsorbent & $q_{\mathrm{m}}\left(\mathrm{mg} \mathrm{g}^{-1}\right)$ & Reference \\
\hline Na-montmorillonite & 3.22 & 64 \\
Granular activated carbon & 2.54 & 65 \\
Dolomite & 2.21 & 66 \\
Tannic acid immobilized activated carbon & 1.73 & 67 \\
Marble & 1.20 & 66 \\
Pithacelobium dulce carbon & 0.41 & 68 \\
GP & 16.45 & This work \\
GO & 41.67 & This work \\
GO-NH & 161.29 & This work
\end{tabular}

isotherm $\left(R^{2}>0.88\right)$. It corresponds to the homogenous adsorbent surface. The $\mathrm{Mn}$ (II) ions were taken place only at specific sites of the GO and GO- $\mathrm{NH}_{2}$ adsorbents, which is valid for monolayer sorption onto a surface. The maximum values of adsorption capacity were $16.45,41.67$ and $161.29 \mathrm{mg} \mathrm{g}^{-1}$ for GP, GO and $\mathrm{GO}-\mathrm{NH}_{2}$, respectively. For comparison, the maximum adsorption capacities of $\mathrm{Mn}$ (II) using other adsorbents are presented in Table 5. It is evident that GO- $\mathrm{NH}_{2}$ possesses high adsorption capacity for $\mathrm{Mn}$ (II) removal from aqueous solution compared with the other carbon-based adsorbents.

\section{Conclusion}

The present study reveals the feasibility of using graphene oxide (GO) functionalized with 3-mercaptopropyl-trimethoxysilane for removal of $\mathrm{Mn}$ (II) from aqueous solution. FTIR and EDX were used to successfully confirm the amino-functionalized GO. Their adsorption behaviors are well described by Langmuir and Freundlich isotherm models. The maximum adsorption capacity of GO- $\mathrm{NH}_{2}$ for $\mathrm{Mn}$ (II) was $161.29 \mathrm{mg} \mathrm{g}^{-1}$. The adsorption process of $\mathrm{Mn}$ (II) follows the pseudo-second-order kinetics model, indicating that the overall rate of $\mathrm{Mn}$ (II) uptake is controlled by external mass transfer at the initial stage of adsorption. In addition, the driving forces that control the adsorption rate later are attributable to intra-particle diffusion. Thermodynamic study of the adsorption process revealed that it was mainly an exothermic spontaneous reaction. Therefore, the present study provides an excellent adsorbent for Mn(II) ions from aqueous solution. This adsorbent can also potentially be used for wastewater treatment.

\section{Conflicts of interest}

The authors have declared no conflict of interest.

\section{Acknowledgements}

This research was financially supported by Materials Chemistry Research Center, Department of Chemistry and Center of Excellence for Innovation in Chemistry (PERCH-CIC), Faculty of Science, Khon Kaen University, Thailand, and the Ministry of Science and Technology, Bangkok, Thailand.

\section{References}

1 H. Li, Z. Zhang, S. Tang, Y. Li and Y. Zhang, Ultrason. Sonochem., 2008, 15, 339-343.

2 S. Laki, A. Arabi Shamsabadi, S. S. Madaeni and M. Niroomanesh, RSC Adv., 2015, 5, 84195-84206.

3 P. Dusek, P. M. Roos, T. Litwin, S. A. Schneider, T. P. Flaten and J. Aaseth, J. Trace Elem. Med. Biol., 2015, 31, 193-203.

4 T. Saleh and V. Gupta, Environ. Sci. Pollut. Res., 2012, 19, 1224-1228.

5 A. Mittal, J. Mittal, A. Malviya and V. K. Gupta, J. Colloid Interface Sci., 2010, 344, 497-507.

6 A. Mittal, J. Mittal, A. Malviya and V. K. Gupta, J. Colloid Interface Sci., 2009, 340, 16-26. 
7 A. Mittal, D. Kaur, A. Malviya, J. Mittal and V. K. Gupta, J. Colloid Interface Sci., 2009, 337, 345-354.

8 V. K. Gupta and A. Nayak, Chem. Eng. J., 2012, 180, 81-90.

9 V. K. Gupta, A. Mittal, D. Jhare and J. Mittal, RSC Adv., 2012, 2, 8381-8389.

10 V. K. Gupta, I. Ali, T. A. Saleh, A. Nayak and S. Agarwal, RSC Adv., 2012, 2, 6380-6388.

11 A. Asfaram, M. Ghaedi, S. Agarwal, I. Tyagi and V. Kumar Gupta, RSC Adv., 2015, 5, 18438-18450.

12 A. K. Jain, V. K. Gupta, A. Bhatnagar and A. Suhas, Sep. Sci. Technol., 2003, 38, 463-481.

13 V. K. Gupta, R. Jain, A. Nayak, S. Agarwal and M. Shrivastava, Mater. Sci. Eng., C, 2011, 31, 1062-1067.

14 V. K. Gupta, S. Agarwal and T. A. Saleh, J. Hazard. Mater., 2011, 185, 17-23.

15 R. K. Mishra, P. C. Rout, K. Sarangi and K. C. Nathsarma, Trans. Nonferrous Met. Soc. China, 2016, 26, 301-309.

16 H. Abu Hasan, S. R. Sheikh Abdullah, S. K. Kamarudin and N. Tan Kofli, Process Saf. Environ. Prot., 2013, 91, 415-422.

17 A. M. Silva, E. C. Cunha, F. D. R. Silva and V. A. Leão, J. Cleaner Prod., 2012, 29-30, 11-19.

18 L. Charerntanyarak, Water Sci. Technol., 1999, 39, 135-138.

19 L. Stoica, M. Dinculescu and C. G. Plapcianu, Water Res., 1998, 32, 3021-3030.

20 O. N. Kononova, G. L. Bryuzgina, O. V. Apchitaeva and Y. S. Kononov, Arabian J. Chem., 2015, DOI: 10.1016/ j.arabjc.2015.05.021.

21 Y. C. Sharma, Uma, S. N. Singh, Paras and F. Gode, Chem. Eng. J., 2007, 132, 319-323.

22 S. R. Taffarel and J. Rubio, Miner. Eng., 2010, 23, 1131-1138.

23 M. P. Tavlieva, S. D. Genieva, V. G. Georgieva and L. T. Vlaev, J. Mol. Liq., 2015, 211, 938-947.

24 A. Ates and G. Akgül, Powder Technol., 2016, 287, 285-291.

25 L. Ma, Y. Peng, B. Wu, D. Lei and H. Xu, Chem. Eng. J., 2013, 225, 59-67.

26 K. Z. Al-Wakeel, H. Abd El Monem and M. M. H. Khalil, J. Environ. Chem. Eng., 2015, 3, 179-186.

27 M. S. Islam, M. S. Rahaman and J. H. Yeum, Colloids Surf., A, 2015, 484, 9-18.

28 P. Nuengmatcha, R. Mahachai and S. Chanthai, Asian J. Chem., 2014, 26, S85-S88.

29 G. Zhao, T. Wen, X. Yang, S. Yang, J. Liao, J. Hu, D. Shao and X. Wang, Dalton Trans., 2012, 41, 6182-6188.

30 G. Zhao, X. Ren, X. Gao, X. Tan, J. Li, C. Chen, Y. Huang and X. Wang, Dalton Trans., 2011, 40, 10945-10952.

31 G. Zhao, J. Li, X. Ren, C. Chen and X. Wang, Environ. Sci. Technol., 2011, 45, 10454-10462.

32 R. Sitko, E. Turek, B. Zawisza, E. Malicka, E. Talik, J. Heimann, A. Gagor, B. Feist and R. Wrzalik, Dalton Trans., 2013, 42, 5682-5689.

33 L. Liu, S. Liu, Q. Zhang, C. Li, C. Bao, X. Liu and P. Xiao, J. Chem. Eng. Data, 2013, 58, 209-216.

34 P. Nuengmatcha, R. Mahachai and S. Chanthai, Asian J. Chem., 2015, 27, 4167-4170.

35 C. J. Madadrang, H. Y. Kim, G. Gao, N. Wang, J. Zhu, H. Feng, M. Gorring, M. L. Kasner and S. Hou, ACS Appl. Mater. Interfaces, 2012, 4, 1186-1193.
36 S. Park, D. A. Dikin, S. T. Nguyen and R. S. Ruoff, J. Phys. Chem. C, 2009, 113, 15801-15804.

37 F. Fang, L. Kong, J. Huang, S. Wu, K. Zhang, X. Wang, B. Sun, Z. Jin, J. Wang, X.-J. Huang and J. Liu, J. Hazard. Mater., 2014, 270, 1-10.

38 Y. Xue, Y. Liu, F. Lu, J. Qu, H. Chen and L. Dai, J. Phys. Chem. Lett., 2012, 3, 1607-1612.

39 S. H. Ryu, J. H. Sin and A. M. Shanmugharaj, Eur. Polym. J., 2014, 52, 88-97.

40 Y. Wang, Z. Shi, J. Fang, H. Xu and J. Yin, Carbon, 2011, 49, 1199-1207.

41 X.-Z. Tang, W. Li, Z.-Z. Yu, M. A. Rafiee, J. Rafiee, F. Yavari and N. Koratkar, Carbon, 2011, 49, 1258-1265.

42 W. Zhang, J. Ma, D. Gao, Y. Zhou, C. Li, J. Zha and J. Zhang, Prog. Org. Coat., 2016, 94, 9-17.

43 L. Chen, D. Zhao, S. Chen, X. Wang and C. Chen, J. Colloid Interface Sci., 2016, 472, 99-107.

44 C. Wang, Y. Lan, W. Yu, X. Li, Y. Qian and H. Liu, Appl. Surf. Sci., 2016, 362, 11-19.

45 M. Ghorbani, S. M. Nowee, N. Ramezanian and F. Raji, Hydrometallurgy, 2016, 161, 117-126.

46 Y. Pei, C. Xiao, T.-W. Goh, Q. Zhang, S. Goes, W. Sun and W. Huang, Surf. Sci., 2016, 648, 299-306.

47 J. Ou, M. Mei and X. Xu, J. Solid State Chem., 2016, 238, 182188.

48 Z. Bian, X. Meng, M. Tao, Y. Lv and Z. Xin, J. Mol. Catal. A: Chem., 2016, 417, 184-191.

49 Z. Rahimi, A. A. L. Zinatizadeh and S. Zinadini, J. Ind. Eng. Chem., 2015, 29, 366-374.

50 L. Hao, T. Zheng, J. Jiang, G. Zhang and P. Wang, Chem. Eng. J., 2016, 292, 163-173.

51 S. Bao, L. Tang, K. Li, P. Ning, J. Peng, H. Guo, T. Zhu and Y. Liu, J. Colloid Interface Sci., 2016, 462, 235-242.

52 P. Nuengmatcha, R. Mahachai and S. Chanthai, Asian J. Chem., 2014, 26, 1321-1323.

53 W. S. Hummers and R. E. Offeman, J. Am. Chem. Soc., 1958, 80, 1339.

54 D. K. Mondal, B. K. Nandi and M. K. Purkait, J. Environ. Chem. Eng., 2013, 1, 891-898.

55 A. Omri and M. Benzina, Alexandria Eng. J., 2012, 51, 343350.

56 S. Netpradit, P. Thiravetyan and S. Towprayoon, Water Res., 2003, 37, 763-772.

57 P. L. Prabha, S. A. F. Rani, T. Ramachandramoorthy and B. Jayalakshmi, World J. Pharm. Pharm. Sci., 2015, 4, 714-723.

58 A. Mittal, V. Thakur and V. Gajbe, Environ. Sci. Pollut. Res., 2013, 20, 260-267.

59 M. Hadavifar, N. Bahramifar, H. Younesi and Q. Li, Chem. Eng. J., 2014, 237, 217-228.

60 G. Vijayakumar, R. Tamilarasan and M. Dharmendirakumar, J. Mater. Environ. Sci., 2012, 3, 157-170.

61 P. Saha, S. Chowdhury, S. Gupta and I. Kumar, Chem. Eng. J., 2010, 165, 874-882.

62 V. Vadivelan and K. V. Kumar, J. Colloid Interface Sci., 2005, 286, 90-100. 
63 H. Tang, W. Zhou and L. Zhang, J. Hazard. Mater., 2012, 209210, 218-225.

64 O. Abollino, M. Aceto, M. Malandrino, C. Sarzanini and E. Mentasti, Water Res., 2003, 37, 1619-1627.

65 A. Bin Jusoh, W. H. Cheng, W. M. Low, A. Nora'aini and M. J. Megat Mohd Noor, Desalination, 2005, 182, 347-353.
66 A. A. Kroik, O. N. Shramko and N. V. Belous, Sewage cleaning with applying of natural sorbents, Chem. Technol. Water, 1999, 21(3), 310.

67 A. Üçer, A. Uyanik and Ş. F. Aygün, Sep. Purif. Technol., 2006, 47, 113-118.

68 K. A. Emmanuel and A. Veerabhadra Rao, Rasayan J. Chem., 2008, 1(4), 840-852. 